\title{
Assessment for Projects of Water Resources Development based on Decision-making Model
}

\author{
Ping $\mathrm{He}$ \\ Wuhan Universtiy, Wuhan, China \\ heping222@hotmail.com
}

\begin{abstract}
The sustainable development of water resources is the decisions making not only on the multi-levels but also on the multi-fields. This paper established a set of social assessment system on water resources projects which based on the theoretical model and the decision-making model of trust relationship from the perspective of risk, and use the items of technical and economic as well, to meet the need of the assessment for sustainable development of water resources projects. Meanwhile, the remarkable social benefits assessment is one of the most important parts in the whole assessment system.
\end{abstract}

Keywords: Decision making; assessment; water resources projects

\section{Introduction}

Water Resources is the backbone in the National Economy. It gets more important to develop the abundant water resources with the carrying out of the Western Development Strategy. Being the recyclable and environment resources, its developing strategy has been changed from traditional type to modern ones, as well as from the one purpose construction to sustainable development. To speed the construction of the infrastructure and follow the international rules, it is necessary to get support from the government finance, and seek the international investment from multi-resources as well. The same question is found both in construction managements and in real estate managements, IT industry (such as software development), shipbuilding managements and venture capital firms, and the common characteristic of these managements is that company business is established and embodied on project level directly. And in order to achieve the strategic objectives of organizations, these managements face the common question that how to manage relative water water resource in a unified way. Research of trust relationship is a research subject developed in recent twenty years. As the effective supplement and extension of traditional security mechanism, trust has become a more flexible and more effective security mechanism to adapt to the dynamic environment. It made the tasks of request service and provision service between entities more elaborated. Throughout the study of trust, numerous native and foreign scholars have proposed various trust relationship models in the open environment [1-3], which has promoted the research and the development of related theory of trust relationship. However, it is difficult for us to grasp and understand the nature of trust relationship because of the complexity of the concept of trust. Too many problems remain unsolved. This paper puts forward a new definition based on the theoretical and decision-making model of water resource management.

\section{Water Resource Management}

Management strategy needs to be supported by multiple projects, but with expanded project scale and increased quantities, managers in old project management framework are apt to delay information acquisition and processing, postpone decision-making and weaken control, making projects difficult to reach the expectation in time limit, expenses 
and other objectives, and ultimately causing bad influence on the successful implementation of management strategy. In order to solve these problems, some scholars and research institutions put forward the concept of water resource management.

\subsection{The Concept of Water Resource Management}

The definition of water resource management made by Ferns was that water resource as a coordinating mechanism for projects that enabled otherwise unrealizable benefits to be extracted [4]. Pellegrinelli proposed his own definition based on that of Ferns: a program as a framework for grouping existing projects or defining new projects, and for focusing all the activities required to achieve a set of major benefits. Lycett and Burke defined water resource management as the integration and management of a group of related projects with the intention of achieving benefits that would not be realized if the projects were managed independently $[5,6]$.

The knowledge of project management research institutions on water resource management is mainly to coordinate projects and relative activities (lack of project form). Project Management Institute (PMI) held that water resource management as the centralized coordinated management of a group of projects to achieve the water resource's strategic benefits and objectives .The Association of Project Management (APM) defined water resource management as the "coordinated management of related projects, which may include related business as usual activities that together achieve a beneficial change of a strategic nature for an organization". The latest version of Managing successful water resources published by the Office of Government Commerce (OGC) defined water resource management as the coordinated organization, direction and implementation of a portfolio of projects and activities that together achieve outcomes and realize benefits that are of strategic importance[7].

The definition of water resource management is controversial both at home and abroad, and different definitions have different emphases. To conclude, these definitions have a lot in common: (1)water resource is composed of related projects; (2) the projects composing water water resource shall be coordinated and managed; (3) water resource management gains additional benefits. While the main differences between these definitions refer to: (1)water water resource includes some daily routines or activities; (2) the elements composing water water resource shall have a unified objective which is always strategic. The diversity of the definition of water resource management is understandable, and even mature project management also has a lot of different representations. It can be found by analyzing these definitions that the main task of water resource management is often defined on the level of project coordination. No doubt coordination is an important task in water resource management, but it is a clear mistake to understand the objective and heart of water resource management as project coordination. The real heart of water resource management is to make managements get, develop, maintain and enhance some ability, because they, after having this ability, can gain expected benefits through successful water resource management.

It should be noted that some scholars and institutions studying project management over a long period of time tend to understand water resource management as an expansion of project management, and solve complex problems occurred in water resource management by adapting, limiting or expanding the theories and methods of project management, such as multi-project delivery, multi-stakeholder, project cooperation, resource sharing and etc. Compared water resource management with project management, it can be found that there are a lot of differences between them (see Table $1)$. 
Table 1. Comparison Table between Water Resource Management and Project Management

\begin{tabular}{|c|c|c|}
\hline Category & Project Management & water resource management \\
\hline Objective & $\begin{array}{c}\text { Fixed objectives (deliverable product } \\
\text { or service) }\end{array}$ & $\begin{array}{c}\text { Vague objectives (strategic objectives or } \\
\text { benefit expectation) }\end{array}$ \\
\hline Environment & $\begin{array}{c}\text { Internal and external environments } \\
\text { easy to be recognized }\end{array}$ & $\begin{array}{c}\text { Changeable external environment and } \\
\text { complex internal boundary }\end{array}$ \\
\hline Life-cycle mode & Linear life cycle & Uncertain life cycle \\
\hline Managers' function & Achieve the success of projects & $\begin{array}{c}\text { Achieve the objectives or benefits of } \\
\text { organizations }\end{array}$ \\
\hline Time and range & Certain time and range & Uncertain time and vague, changeable range \\
\hline Stakeholder & Limited stakeholders & Complex internal and external stakeholders \\
\hline
\end{tabular}

It can be found that water water resource has high uncertainty and fuzziness at the beginning, but with many interested organizations with different expectations, its scale is much larger and internal boundary is much more complex, and its objectives, range and methods are adjusted according to changeable external environment. The characteristics of water resource management are as follows:

(1) water water resource is a framework or structure, without time limit or certain time limit.

(2) water resource management is a means to enhance management ability, focusing on fostering individual and organizational abilities.

(3) water resource management is closely linked with internal and external environments, not a set of universal principle and process with transitivity. In water resource management, managers need to pay special attention to the changes of external environment and strategic objective, and respond to these changes, rather than pursue fixed objective and scale.

In conclusion, water resource management can be defined like this: in order to enhance the abilities of organizations, coordinate and manage related projects (including some relative routines and activities) to achieve the benefits that can not be gained by single management.

\section{Management Trust and Risk in Decision-making Model}

Risk is considered as the nature characteristic of things in many fields. However, up to now, the meaning of the word "risk" remains ambiguous. Different definitions have been proposed by scholars in different fields. This paper introduces following definition according to the requirements on risk issues in information science.

Definition 1. Risk In certain condition and certain period, the grasp of possibility of negative effects on the decision-making target and predictability of harmful consequence of decision-making under the influence of various uncertain factors.

Many scholars [8] have proposed their different views on the concept of trust in the research of trust relationship. So far, same as the risk, there is no uniform definition of trust. But we can find that there is a common point that it emphasis the predictability of the acts of entities. At the same time, only grasping trust relationship from the perspective of risk can reach the nature characteristic of trust relationship and get a clearer concept of trust. We give out the definition of trust from the perspective of risk.

Definition 2. Trust In a particular context, Trustors think that they have ability to accommodate the possible risk brought by the Trustees and they are willing to accept and believe that Trustees' acts can achieve their desired objectives.

The characteristic of concomitant of trust and risk is manifested in that choosing trust means that you are ready to take the risk aroused by trust acts. Meanwhile, when you do 
trust decision-making, you must take risk factors into account and do the decision-making under the control of risk. This is the perceived relationship between trust and risk. What is the nature relationship between trust and risk on earth? To date, there is no final conclusion. Following is several statements with final consensus.

1) Proceeding from the production condition of trust, it is considered that trust can be referred only after the understanding of risk. There is no trust without risk. Risk and trust are two aspects of one problem occurred one by one [9].

2) Trust is a risk-taking behavior. There is a causal relationship between trust and risk, but it is not clear that which is the causation and which is the result [10].

3) There is a reciprocal relationship between trust and risk. Risk provides opportunity for trust, trust creates risk-bearing in return.

All the views above have their correctness and scientificity, but taken together, the relationship between trust and risk is still confused and without a final conclusion. This paper argues that:

1) Trust is another expression of risk, and vice versa. Trust and risk are the expressions of a same thing from different views. Trust is from the perspective of affirmation to obtain the trust degree of thing. Risk is from the perspective of negation to take the potential losses into account. Both are the possibility judgments on results from individuals. They are belonging to the same concept according to the nature. In this sense, the combination of both can make a more objective and comprehensive evaluation for the trust status of the same thing.

2) Trust decision-making is risk decision-making, and vice versa. Trust subject Trustor must take a number of factors into account before deciding whether to make interaction with potential partner Trustee or not. The trust degree on Trustee and the risk evaluation of this interaction are two most important factors. In general, trust decision-making must on the basis of taking risk into account. Similarly, risk decision-making is on the basis on trust. But they are from different views. In a reasonable case, judgment from the same individual for the same thing must be same no matter from the perspective of trust or risk. Only then results are valuable.

Definition 3. Trust Decision-making (TD) In the evaluation of trust relationship, TD is a judgment process that Trustor determines whether and how to response to the Trustee's request according to certain security poly and based on the comprehensive evaluation of Trustee's trust degree and risk measurement value.

Trust decision-making emphasizes that trust and risk should be taken into account at least in the decision-making process, and to determine the final action in accordance with the definition of security policy.

It can be found that trust preference and risk preference are corresponding to each other. Therefore, trust preference and risk preference will be as one, namely individual preference. Thus, trust decision-making is a quaternion. Namely:

$$
\boldsymbol{T} \boldsymbol{D}=(O T D, R F V, \tau, T W)
$$

$O T D$ is the total trust degree, $R F V$ is the total risk measurement value, $\tau$ is individual preference, $T W$ is the importance of transaction.

Trust decision-making is divided into two stages:

One is ascertaining the trust relationship status and the acceptable sets of trust relationship status according to the classification standard of trust grade and risk grade. Trustor ensures the current trust relationship status according to his total trust degree OTD to Trustee and the risk measurement value $R F V$.

Another is judging whether to accept Trustee's request according to Trustor's preference $\tau$, the importance of transaction $T W$ and the certain security poly.

The first stage is to define the classification standard of trust grade and risk grade respectively [11]. Trust degree is classified into seven discrete statuses which 
corresponding to different trust intervals respectively. Similarly, the risk degree is classified into seven discrete statuses as well which is corresponding to different risk intervals respectively, as shown in Table 2. From the classification standard of comprehensive trust grade and risk grade, we can get the trust relationship status from the perspective of risk, as shown in Table 3.

Table 2. The Classification Standard of Trust Grade and Risk Grade

\begin{tabular}{c|c|c|c}
\hline Trust grade & The range of trust degree & Risk grade & The range of risk evaluation \\
\hline Completely distrust & {$[0.00,0.10]$} & $\begin{array}{c}\text { Absolutely } \\
\text { high risk }\end{array}$ & {$[0.90,1.00]$} \\
\hline Quite distrust & $(0.10,0.30]$ & High risk & {$[0.70,0.90)$} \\
\hline Not too trust & $(0.30,0.50)$ & $\begin{array}{c}\text { Relatively high } \\
\text { risk }\end{array}$ & $(0.50,0.70)$ \\
\hline General trust & 0.50 & General risk & 0.50 \\
\hline Relatively trust & $(0.50,0.70]$ & $\begin{array}{c}\text { Relatively low } \\
\text { risk }\end{array}$ & {$[0.30,0.50)$} \\
\hline Quite trust & $(0.70,0.90]$ & Low risk & {$[0.10,0.30)$} \\
\hline Completely trust & $(0.90,1.00]$ & $\begin{array}{c}\text { Absolutely low } \\
\text { risk }\end{array}$ & {$[0.00,0.10)$} \\
\hline
\end{tabular}

Table 3. Status of Trust Relationship from the Perspective of Risk

\begin{tabular}{l|l|l|l|l|l|l|l}
\hline & $\begin{array}{l}\text { Absolutely } \\
\text { high risk }\end{array}$ & $\begin{array}{l}\text { High } \\
\text { risk }\end{array}$ & $\begin{array}{l}\text { Relatively } \\
\text { high risk }\end{array}$ & $\begin{array}{l}\text { General } \\
\text { risk }\end{array}$ & $\begin{array}{l}\text { Relatively } \\
\text { low risk }\end{array}$ & Low risk & $\begin{array}{l}\text { Absolutely } \\
\text { low risk }\end{array}$ \\
\hline Completely distrust & $\mathrm{TS}_{49}$ & $\mathrm{TS}_{42}$ & $\mathrm{TS}_{35}$ & $\mathrm{TS}_{28}$ & $\mathrm{TS}_{21}$ & $\mathrm{TS}_{14}$ & $\mathrm{TS}_{7}$ \\
\hline Quite distrust & $\mathrm{TS}_{48}$ & $\mathrm{TS}_{41}$ & $\mathrm{TS}_{34}$ & $\mathrm{TS}_{27}$ & $\mathrm{TS}_{20}$ & $\mathrm{TS}_{13}$ & $\mathrm{TS}_{6}$ \\
\hline Not too trust & $\mathrm{TS}_{47}$ & $\mathrm{TS}_{40}$ & $\mathrm{TS}_{33}$ & $\mathrm{TS}_{26}$ & $\mathrm{TS}_{19}$ & $\mathrm{TS}_{12}$ & $\mathrm{TS}_{5}$ \\
\hline General trust & $\mathrm{TS}_{46}$ & $\mathrm{TS}_{39}$ & $\mathrm{TS}_{32}$ & $\mathrm{TS}_{25}$ & $\mathrm{TS}_{18}$ & $\mathrm{TS}_{11}$ & $\mathrm{TS}_{4}$ \\
\hline Relatively trust & $\mathrm{TS}_{45}$ & $\mathrm{TS}_{38}$ & $\mathrm{TS}_{31}$ & $\mathrm{TS}_{24}$ & $\mathrm{TS}_{17}$ & $\mathrm{TS}_{10}$ & $\mathrm{TS}_{3}$ \\
\hline Quite trust & $\mathrm{TS}_{44}$ & $\mathrm{TS}_{37}$ & $\mathrm{TS}_{30}$ & $\mathrm{TS}_{23}$ & $\mathrm{TS}_{16}$ & $\mathrm{TS}_{9}$ & $\mathrm{TS}_{2}$ \\
\hline Completely trust & $\mathrm{TS}_{43}$ & $\mathrm{TS}_{36}$ & $\mathrm{TS}_{29}$ & $\mathrm{TS}_{22}$ & $\mathrm{TS}_{15}$ & $\mathrm{TS}_{8}$ & $\mathrm{TS}_{1}$ \\
\hline
\end{tabular}

It can be seen from the Table 3 that trust relationship status reaches to an optimal status gradually in the evolution process from the worst status $\mathrm{TS}_{49}$ of "completely distrustabsolutely high risk" in the top left corner to the right, the bottom, and the bottom right corner. The best status is the $\mathrm{TS}_{1}$ of "completely trust- absolutely low risk" in the bottom right corner. Assume that, the acceptable set of trust relationship status is $\mathrm{TS}_{\text {accept }}=\left\{\mathrm{TS}_{i} \mid i\right.$ $=1 \sim 4,8 \sim 11,15 \sim 18,22 \sim 25\}$ (the dark grey area in Table 2). Correspondingly, it can be known that $O T D=0.70, R F V=0.30$ from the trust evaluation system and risk evaluation system. The trust relationship status of entity $i$ and entity $j$ in this interaction is "relatively trust- low risk", namely $\mathrm{TS}_{10}$, it meets $\mathrm{TS}_{10} \in \mathrm{TS}_{\text {accept }}$, it is acceptable.

In order to introduce Trustor's rational judgment to the trust decision-making, Trustor's individual preference $\tau$ and the importance of transactions $T W$ are introduced to the second stage of trust decision-making. For instance, the trust relationship status of entity $i$ and entity $j$ in an interaction evaluation is "not too trust- absolutely low risk", namely status $\mathrm{TS}_{5}$, it does not meet $\mathrm{TS}_{5} \in \mathrm{TS}_{\text {accept }}$, whether the security strategy should reject this interaction? Trustor's rational judgment plays a role now. The individual preference of decision-maker and the importance of transactions are the significant factors should be taken into account in the process of decision-making. If these factors be quantified and be taken into the calculation to do the research, it is no doubt that the effect of subjective deviation will be avoid. But, these factors can hardly be quantified. Secondly, even if these factors can be quantified, whether the quantification result can match the reality? Thirdly, is it better than qualitative analysis to make quantification for the effect from these factors to decision? And so on. Decision-making is a consequence of combined 
action of subjective consciousness and objective condition. Because limitation exists in pure quantification analysis or pure qualitative analysis, the quantification can be made on easy-quantified indicator as much as possible, and the qualitative analysis can be made on hard-quantified indicators only when quantification analysis and qualitative analysis are combined to make the decision more rational and correct.

\section{Organizational Structure of Water Resource Management}

Managers often adopt the method of ratio extension project management during water resource management, such as ratio extension planning management, increasing control node and expanding resource quantity[12]. The advantage of this method is that it lasts the procedure and experience of project management, while its disadvantage is that it easily causes the following problems: (1) management work tends to be complex, bureaucratic and over-controlled; (2the ability to cope with constantly changing business driving force, objective and strategy is limited; 3the mechanized management concept is unable to perceive and improve the flexible problems arising from water resource management. Therefore, in order to avoid these problems and effectively manage water resource, it is necessary to adjust and change organizational structure and function.

\subsection{Water Resource Management Office}

Water resource management, not a simple extension of project management, needs an integral control and coordination, or else it will have adverse influence on effectiveness and efficiency. In addition, it also needs a centralized control unit called water resource management office which is responsible for the centralized management and coordination of all projects within its control range and whose main functions are shown in Figure 1.

\section{water resource Management}

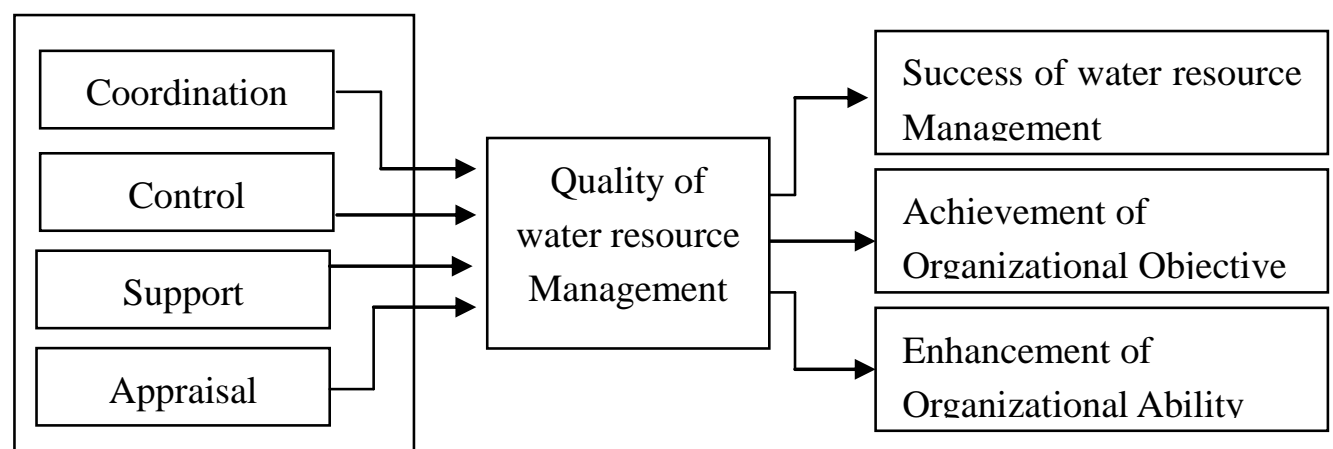

Figure 1. Chart of Water Resource Management Office Function

(1) Coordination role: Allocate limited resources, improve resource utilization, strengthen resource implementation, and ensure rapid resource distribution to minimize the failure of resource distribution. Solve coordination problems of multi-project and trans-department, assist to distinguish and define the internal relations between projects to reduce the frequencies of working accumulation, reworking and delay, and reduce the times of rebuilding management due to lack of interface management between projects. Resolve the conflict between project management and linear management and the power struggle, and mediate between project managers to improve the cooperative quality of cooperation partners.

(2) Control role: Establish a stable, effective information transmission mechanism to collect, build and update the information in water resource and to form an information bank, and provide concrete, accurate and real-time contents to support correct decisions. If necessary, managers can build information trust and promote information sharing with 
stakeholders in a cooperative manner. Enhance the relation between organizational strategies and management activities of implementing these strategies, break up strategic objectives into projects, and ensure more systemic and objective project definition to reduce the probability of project failure and high risk tolerance. Provide higher management transparency for top managers, and better supervise and control the implementation. And provide a feasible framework to adjust the strategies and projects under implementation and to cope with the changing business environment.

(3) Support role: provide services for projects and their managers, enhance managers' and participators' technical levels, and reduce mistakes in cognition and method. Promote the accumulation and spread of organizations on knowledge and the standardization of project management and operation method to enhance the success rate of implementing efficiency and completing projects. Promote and form the organizational culture suitable for water resource management.

(4) Appraisal role: Focus on the expected direction and benefits of water resource, and choose correct, feasible method to distinguish and appraise the benefits achieved within and without its life cycle. Attention should be paid both to the benefits of funds form and to some intangible, unmeasurable benefits, such as enhancing customer satisfaction, reducing error probability, improving workload and work capacity, increasing the flexibility of work force, saving operation expense, and accelerating training process. When the expected benefits of water resource can not be broke up into and distributed to projects directly and clearly, managers should choose a reasonable method to check and appraise these projects.

Water resource management office, which plays an important role in water resource management, may cause conflicts and contradictions with project managers or functional managers when exercising its functions. In order to avoid the diffusion of value creation activities and abilities, water resource management office needs to handle these relations in a respectful manner, and tries not to exert pressure to save from a tense relation. Moreover, the structure of water resource and the power of the office depend on the correlation degree and characteristics of projects as well as wide organization character.

\subsection{Effectiveness Analysis of the Model}

The trust models which considered many risk factors existed many shortcomings because of the essential connotation of risk and trust relationship is not understand thoroughly. This paper proposes the trust relationship model under the perspective of risk, put the risk and trust on equal footing into consideration, enhance the scientific of trust decision.

According to the above analysis and case study, trust relationship model under risk perspective has the following characteristics:

1) Model adopted a trust, risk and credible decision- integrated structure, reflects the effect of subjective and objective factors in the trust decision, it is more reasonable and effective compared to rely on simply trust or risk decision-making.

2) The model introduces the risk to evaluate of the trust relationship, formed the trust relationship status viewed from the Angle of risk, make the formation of trust relationship is more comprehensive and objective.

3) The model has a good dynamic adaptability capacity, it suitable for dynamic requirements of the safety decision-making in open network environment. It suitable for personal preference and the importance of a transaction and further illustrates dynamic adaptability of the model in different environment.

4) The model achieved the quantify relationship of trust, risk and credible decisions, while changing the view that the most existing model considered the risk is just a decision attribute of trust, equate risk with trust, combined the quantitative and qualitative analysis, make the decision making process more effective, more in line with the nature characteristic of the trust, risk and decision making. 


\section{Conclusion}

Trust mechanism provides a new train of thought to solve the problem of information security, make up for the traditional security mechanism cannot adapt to the limitations of dynamic environment on the safety requirements. However, trust and risk together, to accurately grasp the essence of the trust relationship, it must be understand trust relationship under the risk perspective. In this article, through in-depth study of the essence of trust and risk model used in water resource management, put forward clearly trust and risk, as well as the relationship between trust and risk decision, equate risk with trust, given the trust relationship theory model and decision model under the risk perspective. Through analysis of the security decision-making process which integrated trust, risk and trust decision, enhanced the scientific of security decisions, make the security decisions more rational, comprehensive and objective.The theory of water resource programme management is still under development, and its theoretical system and approach remain to be improved. Affected by the ineradicable concept and approach of project management, "multi-project management", "program management" and other wordings, various definitions made by domestic and foreign scholars and research institutions, as well as orientations in management mode, organizational structure and organizational functions, water resource programme management embodies varying erroneous tendencies during the implementation, weakening organizations' ability to acquire benefits. Undoubtedly, it is a key for successful water resource programme to establish a correct concept of water resource programme management and adjust the structure and functions of organizations.

\section{References}

[1] C. Duma and N. Shahmehri, "Dynamic trust metrics for peer-to-peer system", Proc. of the 16th Int'1 Workshop on Database and Expert Systems Applications (DEXA) Washington, IEEE Computer Society Press, (2005).

[2] K. Shao, F. Luo, N. X. Mei and Z. T. Liu, "Normal Distribution Based Dynamical Recommendation Trust Model", Journal of Software, vol. 23, no. 12, (2012 ), pp:3130-3148.

[3] S. S. Song, K. Hwang and M. Macwan, "Fuzzy trust integration for security enforcement in grid computing", Proc. of the Int'l Symp. on Network and Parallel Computing, LNCS 3222, Berlin: Springer-Verlag, (2004).

[4] W. Tang and Z. Chen, "Research of Subjective Trust Management Model Based on the Fuzzy Set Theory", Journal of Software, vol. 14, no. 8, (2003), pp: 1401-1408.

[5] F. J. Yu, H. G. Zhang and F. Yan, "A Fuzzy Relation Trust Model in P2P System”, Proceeding of the International Conference on Computational Intelligence and Security (CIS) Part 2, IEEE Press, (2006).

[6] X. Y. Li and X. L. Gui, "Research on Dynamic Trust Model for Large Scale Distributed Environment", Journal of Software, vol. 18, no. 6, (2007), pp. 1510-1521.

[7] D. W. Manchala, "Trust metrics, models and protocols for electronic commerce transactions", The 18th International Conference on Distributed Computing Systems, (1998).

[8] A. Jøsang, D. Bradley and S. J. Knapskog, "Belief -Based Risk Analysis", ACSW Frontiers, (2004).

[9] Z. Shehu and A. Akintoye, "Construction programme management theory and practice: Contextual and pragmatic approach “, International Journal of Project Management, vol. 27, (2009), pp. 703-716.

[10] "The Standard for Program Management", Project Management Institute, (2006).

[11] "The Association for Project Management Body of Knowledge", APM: High Wycombe, (2000).

[12] "Managing successful programmes", UK: Office of Government Commerce OGC, The Stationery Office, (2007).

\section{Author}

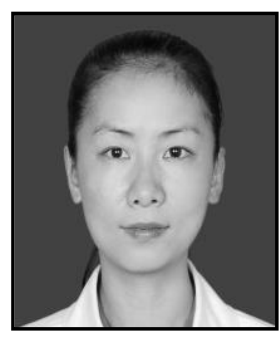

Ping He, (1982-) research direction: program management PHD in Wuhan University. 